\title{
CPR63 promotes pyrethroid resistance by increasing cuticle thickness in Culex pipiens pallens
}

\author{
Yang $X u^{1,2}$, Jingwei Xu' ${ }^{1}$, Yang Zhou ${ }^{1}$, Xixi Li ${ }^{2}$, Yufen Meng ${ }^{2}$, Lei Ma ${ }^{1}$, Dan Zhou ${ }^{1}$, Bo Shen ${ }^{1}$, Yan Sun ${ }^{1 *}$ and \\ Changliang Zhu'
}

\begin{abstract}
The cuticle protein (CP) encoded by CPR63 plays a role in deltamethrin resistance in Culex pipiens pallens. Herein, we investigated the distribution of CPR63 transcripts in this organism and observed high expression levels in legs and wings. Furthermore, expression of CPR63 in the legs of deltamethrin-resistant (DR) strains was 2.17-fold higher than in deltamethrin-susceptible (DS) strains. Cuticle analysis of small interfering RNA (siRNA) groups by scanning electron microscopy (SEM) revealed a significantly thinner cuticle of the tarsi in the siCPR63 group than in the siNC (negative control siRNA) group. Transmission electron microscopy (TEM) revealed that the exocuticle and endocuticle thickness of the tarsi were significantly thinner, which contributes the thinner procuticle of tarsi in the siCPR63 group than in the siNC group. Our results suggested that CPR63 might contribute to the resistance phenotype by thickening the cuticle and thereby possibly increasing the tolerance of mosquitoes to deltamethrin.
\end{abstract}

Keywords: CPRs, Deltamethrin, Mosquito, Culex pipiens pallens, Cuticular resistance, Cuticle thickening

\section{Introduction}

Targeting insect vectors has proven to be the most effective means for preventing the spread of mosquito-borne diseases $[1,2]$. Chemical insecticides are the most important component in this effort. However, the spread of insecticide resistance seriously threatens the success and sustainability of control interventions [3]. According to the latest World malaria report, 73 countries reported mosquito resistance to at least one of the four commonly used insecticide classes during 2010-2019, and 28 countries reported mosquito resistance to all major insecticide classes [4]. Therefore, it is critical to develop and apply effective insecticide resistance management strategies.

*Correspondence: sunyan@njmu.edu.cn

1 Department of Pathogen Biology, Nanjing Medical University, Nanjing, China

Full list of author information is available at the end of the article
Research on the mechanism of mosquito vector resistance is of great significance for mosquito vector control. Generally, insecticide resistance in insects is caused by three major mechanisms: (i) reduced sensitivity of the target site, (ii) increased activity and/or abundance of detoxification enzymes and (iii) reduced penetration of insecticides due to altered cuticles [5]. The cuticle is believed to function in insecticide resistance by reducing or slowing insecticide uptake. Various CPs (CPR, CPAPn, CPG, CPF and CPLCG) belonging to different protein families have been identified [6,7]. Some cuticle proteins (CPs) play major roles in insecticide resistance in mosquitoes. For example, previously, CPLCG3, CPLCG4 and CPLCG5 were involved in a putative cuticle thickening mechanism. CPR124, CPR127, CPR129 and CPR131 were found expressed at higher levels in pyrethroid-resistant compared to susceptible mosquitoes [14, 24, 25, 27]. Most CPs belong to the CPR family and possess characteristic Rebers and Riddiford (R\&R) consensus original author(s) and the source, provide a link to the Creative Commons licence, and indicate if changes were made. The images or other third party material in this article are included in the article's Creative Commons licence, unless indicated otherwise in a credit line to the material. If material is not included in the article's Creative Commons licence and your intended use is not permitted by statutory regulation or exceeds the permitted use, you will need to obtain permission directly from the copyright holder. To view a copy of this licence, visit http://creativecommons.org/licenses/by/4.0/. The Creative Commons Public Domain Dedication waiver (http://creativecommons.org/publicdomain/zero/1.0/) applies to the data made available in this article, unless otherwise stated in a credit line to the data. 
sequences (RR-1 and RR-2) that in an extended form confer chitin-binding properties [8-11]. In a recent study, the location of RR-1 s and RR-2 s was found to be more dependent on the properties of individual proteins than had been reported in previous work [12]. A previous study in our laboratory investigated expression of the CPR63 gene (GenBank: MF095856.1), encoding an RR-2 family member in Cx. pipiens pallens, and this was more abundant in deltamethrin-resistant (DR) than deltamethrin-susceptible (DS) strains [13]. Furthermore, the mosquito mortality rate was altered by silencing the CPR63 gene [13]. However, the detailed resistance mechanism of CPR63 related to the mosquito cuticle remains unknown. In this study, we revealed that CPR63 might participate in pyrethroid resistance by thickening the cuticle and thereby possibly increasing the tolerance of mosquitoes to deltamethrin.

\section{Materials and methods Mosquito strains}

In this study, we collected Cx. pipiens pallens from Tangkou (Shandong Province, China) as DS strains, and the $\mathrm{LC}_{50}$ for deltamethrin for these DS strains was $0.03 \mathrm{mg} / \mathrm{l}$. DR strains were isolated from DS strains with an $\mathrm{LC}_{50}$ of $7.5 \mathrm{mg} / \mathrm{l}$ by repeatedly selecting 84 generations at the larval stage. Other details were as described in a previous study [14].

\section{RNA extraction and CDNA synthesis}

We collected heads, thorax, abdomen, and all legs and wings of the DS and DR female mosquitoes at $72 \mathrm{~h}$ posteclosion (PE) in three tubes for each tissue (20 mosquitoes per tube). Extraction of mosquito total RNA was performed according to the RNAiso Plus instructions (Takara, Shiga, Japan), and the RNA was then converted to cDNA using the PrimeScriptRT Reagent Kit (TaKaRa, Tokyo, Japan).

\section{Quantitative real-time PCR (qPCR)}

cDNA samples were diluted properly with RNase-free water before use as templates in the quantitative PCR process using SYBR Green (Applied Biosystems, Foster City, CA, USA) according to the manufacturer's protocol. The reaction volume $(20 \mu \mathrm{l})$ contained the Power SYBR Green PCR Master Mix, specific forward and reverse primers (Additional file 3: Table S1) and diluted cDNA. The PCR conditions were as follows: $50{ }^{\circ} \mathrm{C}$ for $2 \mathrm{~min}$ and $95^{\circ} \mathrm{C}$ for $10 \mathrm{~min}$, followed by 40 cycles at $95{ }^{\circ} \mathrm{C}$ for $15 \mathrm{~s}$ and $60{ }^{\circ} \mathrm{C}$ for $1 \mathrm{~min}$. For qPCR validation, the melting curve program was run immediately after the qPCR program showed a single-peaked curve. Amplification signals in the no template or primer control samples were high $\mathrm{Ct}$ values $(\mathrm{Ct}>35)$. When the primers were used at the first time, qPCR products were sequenced for confirmation. The correlation coefficients of the calibration curves in each test were $>0.99$. The relative expression levels were normalised to the internal control $\beta$-actin by using the $2^{-\Delta \Delta \mathrm{Ct}}$ method [15-18]: target gene $/ \beta$-actin $=2^{\Delta \mathrm{Ct}}$, $\Delta \mathrm{Ct}=\mathrm{Ct}_{\beta \text {-actin }}-\mathrm{Ct}_{\text {target gene. }}$. Three technical and biological replicates were performed for qPCR analyses.

\section{Gene silencing}

Mosquitoes for RNA interference (RNAi) experiments were derived from DR and DS female strains microinjected at $12 \mathrm{~h} \mathrm{PE}$, with three tubes for each group (10 RNAi mosquitoes per tube). A small interfering RNA (siRNA) targeting CPR63 (siCPR63) and a siNC (negative control siRNA) were synthesised by GenePharma (Shanghai, China; Additional file 3: Table S1). The siNC does not cause any gene silencing and has no homologous genes in the mosquito gene bank. About $364 \mathrm{ng}$ of siCPR63 and $350 \mathrm{ng}$ of siNC were separately injected into the thorax of female mosquitoes. Other details of the gene silencing method have been described previously [15]. After 3 days, qPCR was performed to determine the interference efficiency of the target gene.

\section{Scanning electron microscopy (SEM)}

To avoid the influence of mosquito size on cuticle thickness, we measured the wing length of all female mosquitoes in the experiment [31]. There were 11 female mosquitoes in each group (siNC, siCPR63), and we selected one right front leg from each female mosquito. All microinjected mosquito legs were washed twice in $70 \%$ ethanol to clean them thoroughly. Alcohol was dripped onto tarsomere I of the right front leg at the midpoint, and the leg was cut with a new platinum-coated blade and washed again to remove any debris. Legs were then fixed in $2.5 \%$ glutaraldehyde (Sigma, St Louis, MO, USA) for $12 \mathrm{~h}$ and incubated for $10 \mathrm{~min}$ each in a graded ethanol series $(30,50,70,80$, 90, 95 and 100\%). Legs were dried in an EM CPD300 critical point dryer (Leica, Wetzlar, Germany) using an automated process for 15 exchanges. A K550 X sputter coater (Electron Microscopy Sciences, Hatfield, PA, USA) was used for coating samples. A Quanta 250 FEI scanning electron microscope was employed, and images were recorded at a $3-\mathrm{kV}$ acceleration voltage. The thickness of the cuticle was examined using image J software (http://imagej.net/Welcome). The average cuticle thickness of each leg was calculated by measuring the distance at 23 randomly selected points. 


\section{Transmission electron microscopy (TEM)}

Six female mosquitoes were included in each group (siNC, siCPR63), and we selected one right front leg from each female mosquito (i.e. six legs per group). Tarsi were divided into four equal parts, and 2-3 images were captured for each part, resulting in 9-10 images for each leg and 58 images in total. The thickness of the cuticle was examined using image J software. According to the obtained pictures, we also counted the number of pores in tarsi. The other detailed steps of the TEM experiment have been described in previous studies $[14,19]$.

\section{Statistical analysis}

Experimental data between two groups were analysed using Student's $t$-test. The expression levels of CPR63 in different tissues were calculated using an ANOVA test. All data are presented as the mean \pm standard deviation (SD), and $p<0.05$ was considered statistically significant. All experiments were performed using at least three independent cohorts.

\section{Results}

\section{CPR63 transcripts are abundant in DR mosquito legs}

To explore the function of CPR63, we examined localisation of CPR63 expression in multiple tissues at $72 \mathrm{~h} \mathrm{PE}$ by qPCR in DS and DR strains, including the heads, thorax, abdomen, legs and wings. The results showed that CPR63 was highly expressed in legs. Expression of CPR63 in the legs of DR strains was 2.17-fold higher (ANOVA, $p<0.0001$ ) than those in DS strains (Fig. 1). The result showed that CPR63 was highly expressed in legs and

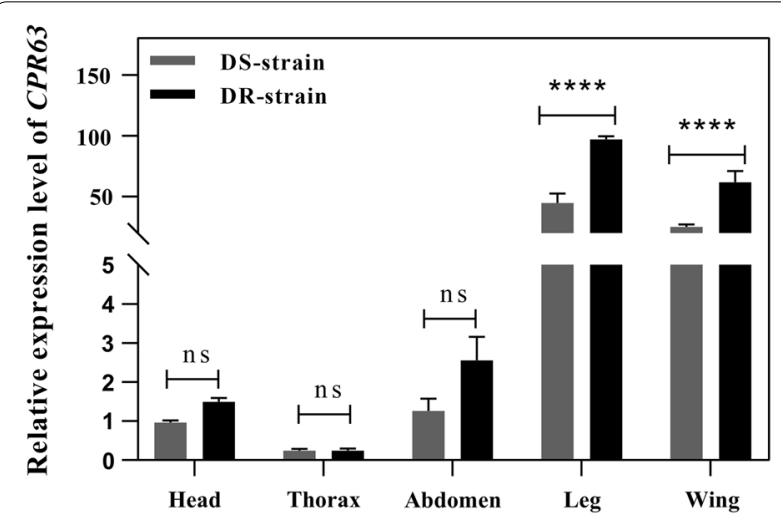

Fig. 1 Expression profiles of CPR63 in different mosquito tissues. Constitutive expression of CPR63 in DS and DR strains; mRNA expression levels were measured in the head, thorax, abdomen, legs and wings in DS and DR strain mosquitos. Head of DS strain was ascribed an arbitrary value of 1 . Results are presented as the mean \pm standard deviation (SD) of three biological replicates. ${ }^{* * * *} p \leq 0.0001 ; n s$, not signifcant, $p>0.05$ indicated that CPR63 might play an important role in leg resistance.

\section{Expression of CPR63 following gene silencing}

Expression of CPR63 was evaluated by qPCR in DR strains at $12 \mathrm{~h} P E$ after injection of siRNA targeting the CPR63 gene. Expression of CPR63 was significantly decreased by $40.9 \%\left(t\right.$-test, $\left.t_{(4)}=2.935, p=0.0426\right)$ in the whole bodies of mosquitoes and by $37.6 \%$ ( $t$-test, $\left.t_{(4)}=3.146, p=0.0347\right)$ in the legs at $72 \mathrm{~h} \mathrm{PE}$ after siCPR63 injection compared to injection with siNC (Fig. 2a, b). We also found that interference efficiency of CPR63 in DS strains is not statistically significant compared with siNC group of DS strains, which could be used as a control (Additional file 2: Figure S2).

\section{SEM analysis of cuticle thickness}

To probe the changes in the overall cuticle structure, the region of the tarsus segment was analysed by SEM. The mosquito leg is composed of the femur, tibia and tarsus, the tarsus is divided into $\mathrm{T} 1, \mathrm{~T} 2, \mathrm{~T} 3, \mathrm{~T} 4$ and $\mathrm{T} 5$, and the cross section was at T1 (Fig. 3a) [19, 20]. The same number of specimens was assessed in siCPR63 and siNC groups $(n=11)$. Mosquito leg tarsi were assessed by comparing the size of the mosquito wing and measuring the area of the inner and outer circles of the mosquito leg cuticle. The results showed that the tarsi were a similar size in the two groups, but they were significantly thinner in the siCPR63 than in the siNC group (Fig. 3b, c). The cuticle thickness was measured at no fewer than 23 random points to obtain the average cuticle thickness of the tarsus. The measurement results showed that the mean cuticle thickness of the siCPR63 group $(1.354 \pm 0.23 \mu \mathrm{m})$ was thinner than that of the siNC group $(2.006 \pm 0.73 \mu \mathrm{m}$; Fig. 4; Table 1 ; $t$-test, $t_{(44)}=3.981, p=0.0011$ ).
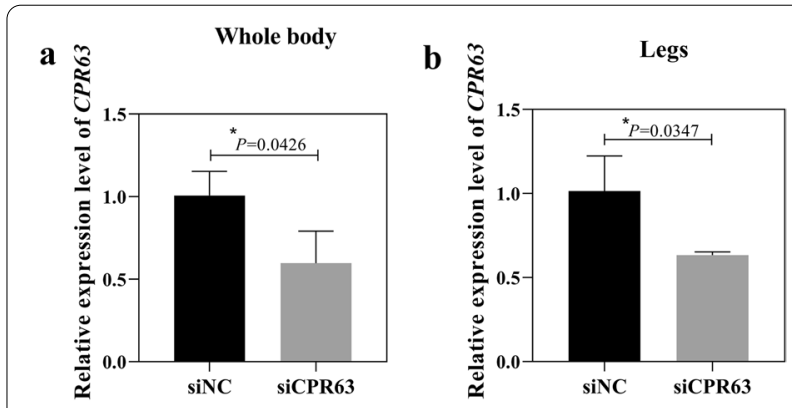

Fig. 2 Relative expression levels of CPR63 after RNAi silencing. Levels of CPR63 expression in whole mosquito bodies (a) and legs (b) after silencing of CPR63 were measured by qPCR. Results are shown as the mean \pm SD of three biological replicates. ${ }^{*} p \leq 0.05 ;{ }^{* *} p \leq 0.01$ 

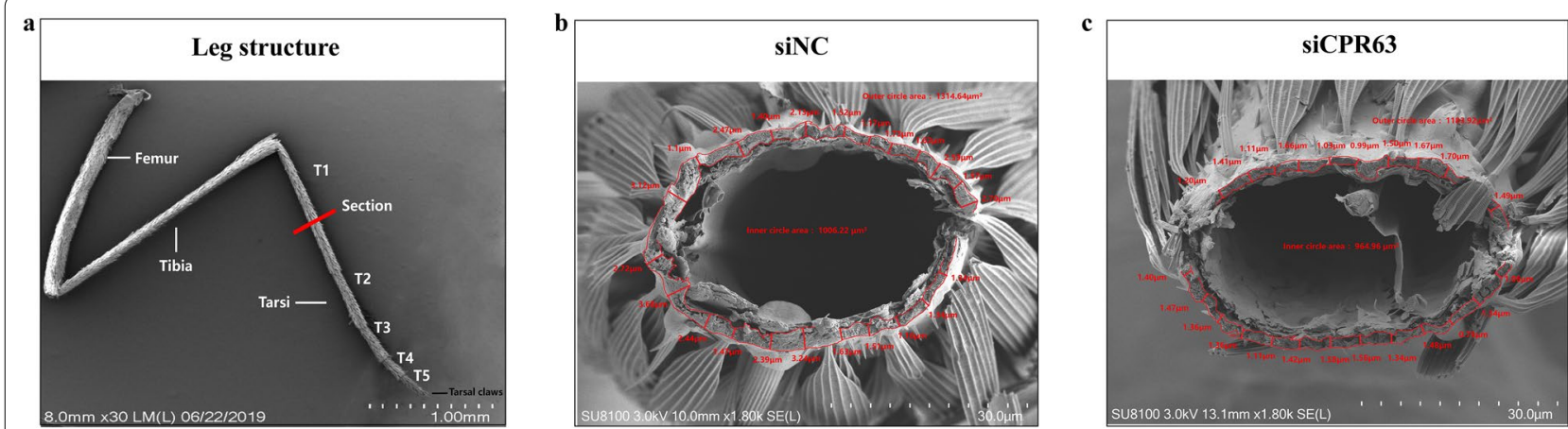

Fig. 3 SEM analysis of the effects of siNC and siCPR63. a lllustration of the position of sectioning on the $C x$. pipiens pallens tarsomere 1 ( $t 1-t 5=f i v e$ tarsal segments) [20]. The red line indicates in which leg part the sections were taken. The SEM images show a front view of a sectioned leg for the siNC group (b) and the siCPR63 group (c)

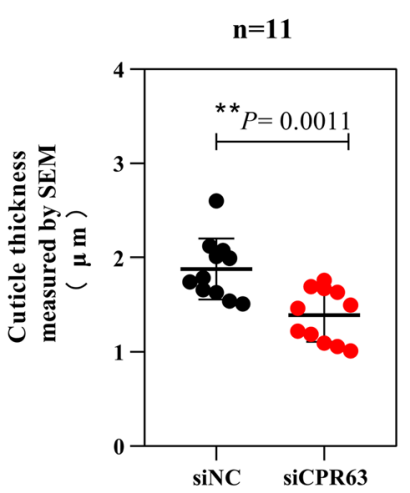

Fig. 4 SEM analysis of cuticle thickness. Measurements were made at 23 different points per individual, allowing for the calculation of mean cuticle thickness. Results are shown as the mean $\pm S D$; $n=$ the number of measurements carried out on each group of 11 mosquitoes. ${ }^{* *} p=0.0011$

\section{Ultrastructure analysis of tarsi segment cuticles in siCPR63 and siNC mosquitoes by TEM}

To explore differences in the cuticle ultrastructure of mosquitoes, the region of the tarsus segment was analysed by TEM. Additional file 1: Figure S1 shows a schematic diagram of how images were captured. The leg cuticle is mainly composed of the procuticle, which is divided into the exocuticle and the endocuticle (Fig. 5).
The results showed that the procuticle thickness of the siCPR63 group $(2.219 \pm 0.86 \mu \mathrm{m})$ was thinner than that of the siNC group $(3.23 \pm 0.74 \mu \mathrm{m}$; Fig. 6a; Table 1 ; $\left.t_{(114)}=6.756, p<0.0001\right)$. The exocuticle and endocuticle thickness of the leg tarsus in the siCPR63 was thinner than in the siNC group (Fig. 6b, c; Table 1). Compared with the siNC group, the chitinous parallel laminae, number and size of pores in the siCPR63 group were comparable to the siNC group (Figs. 5a, b; 6d).

\section{Discussion}

Cuticle proteins play an important role in insect cuticle resistance, by thickening the cuticle to prevent the penetration of insecticides and changing the density, thickness and insect morphological development of the cuticle. There is increasing evidence that alteration of the cuticle plays a role in insecticide resistance, based on analysis of $\mathrm{CP}$ transcripts and measurement of cuticle thickness [19, 21-25]. For example, CYP4G16, CPLCG3, CPLCG5 and CPLC 8 have been implicated in insecticide resistance by contributing to a thicker cuticle and thereby slowing penetration of insecticides [14, 21, 24-26]. Three CPR genes (CPR124, CPR129 and $C P R 127)$ were found to be constitutively overexpressed in resistant Anopheles gambiae [25]. In another study, 31 cuticle proteins were differentially regulated in the leg proteome, of which 29 including CPR106, CPR126,

Table 1 Average cuticle thickness of each component

\begin{tabular}{lllll}
\hline Cuticle & $\begin{array}{l}\text { Procuticle thickness } \\
\text { by SEM }(\mu \mathrm{m})\end{array}$ & $\begin{array}{l}\text { Procuticle thickness } \\
\text { by TEM }(\mu \mathrm{m})\end{array}$ & $\begin{array}{l}\text { Edocuticle thickness } \\
\text { by TEM }(\mu \mathrm{m})\end{array}$ & $\begin{array}{l}\text { Exocuticle } \\
\text { thickness by } \\
\text { TEM }(\mu \mathrm{m})\end{array}$ \\
\hline Group & & & & $1.489 \pm 0.30$ \\
SiNC & $2.006 \pm 0.73$ & $3.239 \pm 0.74$ & $0.924 \pm 0.48$ & $1.609 \pm 0.22$ \\
SiCPR63 & $1.354 \pm 0.23$ & $2.219 \pm 0.86$ & $1.337 \pm 0.36$ \\
\hline
\end{tabular}


$\mathbf{a}$

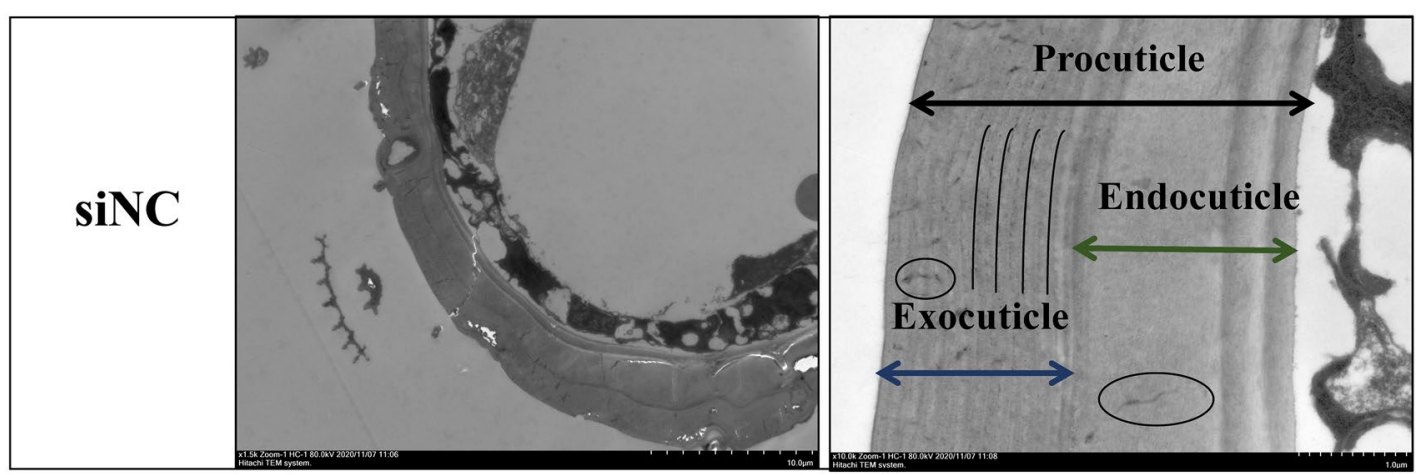

b

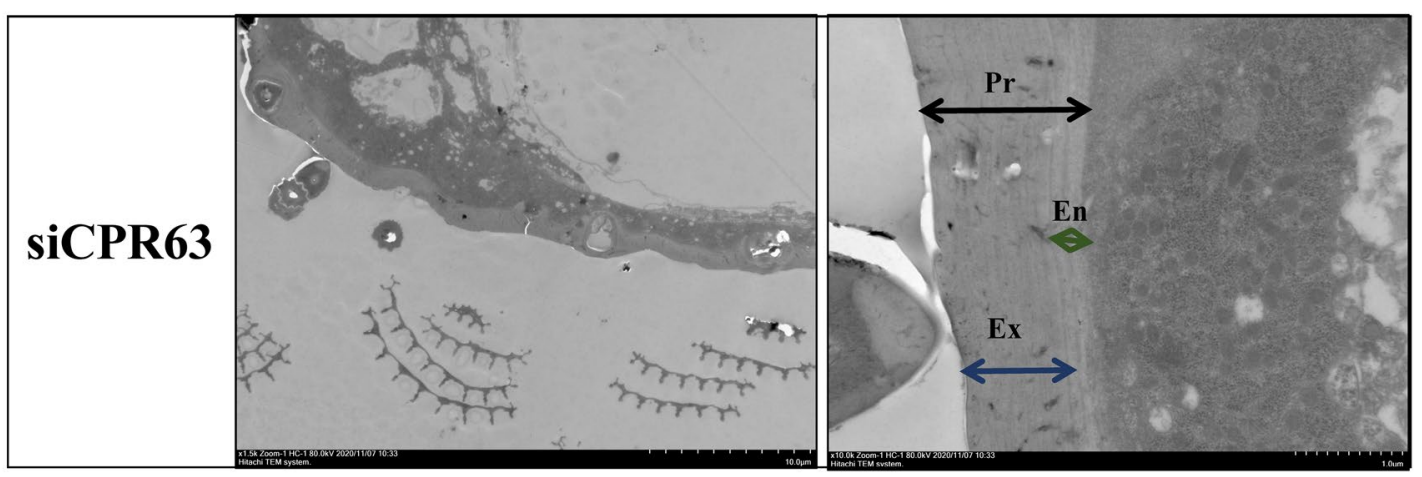

Fig. 5 TEM analysis of the effects of siNC and siCPR63. SEM images show a front view of a sectioned leg for siNC (a) and siCPR63 (b) groups. The curve represents the chitin parallel laminae, and the circle represents the pores
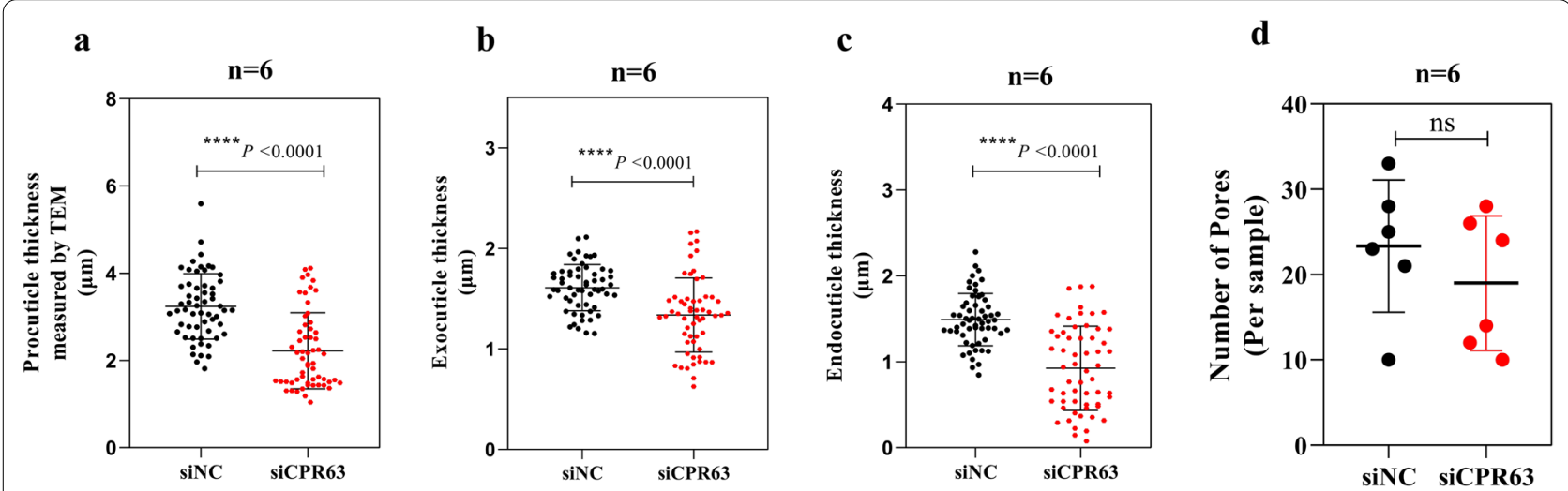

Fig. 6 TEM analysis of cuticle thickness. Measurements were performed at 58 points per individual, allowing for the calculation of mean cuticle thickness. Results are shown as the mean $\pm S D ; n=$ the number of measurements carried out on each batch of six mosquitoes. ${ }^{* * *} p \leq 0.0001 ;$ not signifcant, $p>0.05$

CPR121 and CPR151 were overexpressed, and only 2 were downregulated [22]. Furthermore, $>65 \%$ of differentially expressed CPs belonged to the CPR family. Strong overexpression of cuticle protein CPR131 was also reported in multi-insecticide-resistant $A$. gambiae [27], and CPR63, CPR47, CPR48, CPR45 and CPR44 are highly expressed in DR strains of $C x$. pipiens pallens [13].
Overexpression of CPRs in resistant mosquitoes has been widely reported, but their cuticle resistance mechanisms remain poorly understood. Our previous study found that silencing the CPR63 gene made mosquitoes more susceptible to deltamethrin, suggesting that CPR63 participates in pyrethroid resistance [13]. In the present study, our results led us to speculate about the resistance mechanism by which CPR63 
might contribute to the resistance phenotype; CPR63 is involved in thickening of the cuticle, and thereby possibly increasing the tolerance of mosquitoes to deltamethrin.

Insect CPs are diverse and expressed in the head, thorax and abdomen. Some CPs are also highly expressed in insect legs. For example, CPLCG5 is highly expressed in the legs of $C x$. pipiens pallens [14], and members of the CPCFC CP family in A. gambiae are mainly distributed in legs [28]. Noh et al. found that cuticle protein TcCPR4 in Tribolium castaneum was mainly enriched in the legs and participated in the formation of pore canals in the rigid cuticle [8]. CPF3, CPLCG3, CPLCG4 and CPLCG5 mRNA transcripts were mainly located in appendages (legs and wings) [14, 24]. Similarly, in the present study, CPR63 mRNAs were mainly located in mosquito legs and wings. Since these appendages are associated with motion, CPR63 might be related to flight. Additionally, CPR63 was expressed more highly in the legs of DR strains, indicating that it might help mosquitoes avoid areas treated with insecticides, but this hypothesis requires further exploration.

Different CPs play different roles in cuticular resistance. Huang et al. reported that CPLCG5 acts as a major $\mathrm{CP}$ and is highly expressed in the legs in Cx. pipiens pallens [14]. Our current results showed that expression of CPR63 was increased in insecticide-resistant $C x$. pipiens pallens and also highly expressed in the legs. In addition, silencing of CPLCG5 resulted in larger pore canals, indistinct chitinous parallel laminae and thinner endocuticle in the leg structures. Specifically, silencing of CPR63 resulted in thinner endocuticle and exocuticle, but the chitinous parallel laminae and number and size of pores are not significantly altered, indicating that different CPs perform distinct functions to contribute to cuticular resistance, and CPR63 participates in cuticular resistance mainly by increasing the cuticle thickness.

Early studies suggest that RR-1 and RR-2 proteins are present in different regions within the cuticle itself; RR-2 proteins contribute to exocuticle, and RR-1 proteins are found in the endocuticle [29, 30]. However, a more recent study showed that the location of RR-1 s and RR-2 $\mathrm{s}$ depends more on the properties of individual proteins [12]. Our current study showed that silencing CPR63 led to thinner endocuticle and exocuticle. We therefore speculate that CPR63 may be distributed in both the endocuticle and exocuticle, but this hypothesis needs further verification. In addition, our previous study found that another cuticle protein, CPR47, is also related to insecticide resistance. There may be an interaction between cuticle proteins, but how this affects resistance and whether it is related to CPR63 remain unknown. The work needs further study.
In summary, our results revealed that CPR63 might participate in pyrethroid resistance by thickening the cuticle and thereby possibly increasing the tolerance of mosquitoes to deltamethrin. This is the first report linking CPRs to insecticide resistance in mosquito legs.

\begin{abstract}
Abbreviations
DR: Deltamethrin-resistant; DS: Deltamethrin-susceptible; PE: Post-eclosion; CPs: Cuticle proteins; R\&R: Rebers and Riddiford; qPCR: Quantitative real-time PCR; siRNA: Small interfering RNA; siCPR63: Small interfering RNA for silencing the CPR63 gene; NC: Negative control; siNC: Negative control siRNA; SEM: Scanning electron microscopy; TEM: Transmission electron microscopy.
\end{abstract}

\section{Supplementary Information}

The online version contains supplementary material available at https://doi. org/10.1186/s13071-022-05175-0.

Additional file 1: Figure S1. Schematic diagram showing image capture. Additional file 2: Figure S2. Relative expression levels of CPR63 after RNAi silencing in DS strains.

Additional file 3: Table S1. Primers used for $q P C R$ analysis and siRNA synthesis of CPR63.

Acknowledgements

Not applicable.

\section{Authors' contributions}

$Y X, X J W, Y Z, X X L$ and $Y F M$ performed experiments. $Y X$ and $Y S$ wrote the manuscript and prepared the figures. YS, LM, DZ, BS and CLZ conceived the study and coordinated the project. All authors read and approved the final manuscript.

\section{Funding}

This work was supported by the National Natural Science Foundation of China (grant numbers 81672056, 81772227 and 81672058) and the National Critical Project for $\mathrm{S} \& \mathrm{~T}$ on Infectious diseases P.R. of China (grant number 2017ZX10303404-002-006).

Availability of data and materials

All data are fully available without restriction.

\section{Declarations}

Ethics approval and consent to participate

All animal procedures were approved by the Institutional Animal Care and Use Committee (IACUC) of Nanjing Medical University for the use of laboratory animals (protocol no. 582/2017).

\section{Consent for publication}

Not applicable.

\section{Competing interests}

The authors declare that they have no competing interests.

\section{Author details}

${ }^{1}$ Department of Pathogen Biology, Nanjing Medical University, Nanjing, China. ${ }^{2}$ School of Medicine \& Holistic Integrative Medicine, Nanjing University of Chinese Medicine, Nanjing, China.

Received: 1 August 2021 Accepted: 22 January 2022

Published online: 14 February 2022 


\section{References}

1. Bhatt S, Weiss DJ, Cameron E, Bisanzio D, Mappin B, Dalrymple U, et al. The effect of malaria control on Plasmodium falciparum in Africa between 2000 and 2015. Nature. 2015;526:207-11.

2. Ingham VA, Anthousi A, Douris V, Harding NJ, Lycett G, Morris M, et al. A sensory appendage protein protects malaria vectors from pyrethroids. Nature. 2020:577:376-80.

3. Liu N. Insecticide resistance in mosquitoes: impact, mechanisms, and research directions. Annu Rev Entomol. 2015:60:537-59.

4. WHO P: Word malaria report 2020. World Health Organization 2020

5. Dang K, Doggett SL, Veera-Singham G, Lee C-Y. Insecticide resistance and resistance mechanisms in bed bugs, Cimex spp. (Hemiptera: Cimicidae). Parasit Vectors. 2017;10:318

6. Zhou D, Duan B, Sun Y, Ma L, Zhu C, Shen B. Preliminary characterization of putative structural cuticular proteins in the malaria vector Anopheles sinensis. Pest Manag Sci. 2017;73:2519-28.

7. Zhou Y, Badgett MJ, Billard L, Bowen JH, Orlando R, Willis JH. Properties of the cuticular proteins of Anopheles gambiae as revealed by serial extraction of adults. PLoS ONE. 2017;12:e0175423.

8. Noh MY, Muthukrishnan S, Kramer KJ, Arakane Y. Tribolium castaneum RR-1 cuticular protein TCCPR4 is required for formation of pore canals in rigid cuticle. PLoS Genet. 2015;11(2):e1004963.

9. Karouzou MV, Spyropoulos Y, Iconomidou VA, Cornman RS, Hamodrakas SJ, Willis JH. Drosophila cuticular proteins with the R\&R Consensus: annotation and classification with a new tool for discriminating RR-1 and RR-2 sequences. Insect Biochem Mol Biol. 2007;37:754-60.

10. Cornman RS, Togawa T, Dunn WA, He N, Emmons AC, Willis JH. Annotation and analysis of a large cuticular protein family with the R\&R Consensus in Anopheles gambiae. BMC Genomics. 2008;9:22.

11. Togawa T, Nakato H, Izumi S. Analysis of the chitin recognition mechanism of cuticle proteins from the soft cuticle of the silkworm, Bombyx mori. Insect Biochem Mol Biol. 2004;34:1059-67.

12. Vannini L, Willis JH. Localization of RR-1 and RR-2 cuticular proteins within the cuticle of Anopheles gambiae. Arthropod Struct Dev. 2017:46:13-29.

13. Sun X, Guo J, Ye W, Guo Q, Huang Y, Ma L, et al. Cuticle genes CpCPR63 and CPCPR47 may confer resistance to deltamethrin in Culex pipiens pallens. J Parasitol Res. 2017;116:2175-9.

14. Huang Y, Guo Q, Sun X, Zhang C, Xu N, Xu Y, et al. Culex pipiens pallens cuticular protein CPLCG5 participates in pyrethroid resistance by forming a rigid matrix. Parasit Vectors. 2018;11:6.

15. Zhou D, Duan B, Xu Y, Ma L, Shen B, Sun Y, et al. NYD-OP7/PLC regulatory signaling pathway regulates deltamethrin resistance in Culex pipiens pallens (Diptera: Culicidae). Parasit Vectors. 2018;11:419.

16. Livak KJ, Schmittgen TD. Analysis of relative gene expression data using real-time quantitative PCR and the $2-\triangle \triangle C T$ Method. Methods. 2001;25:402-8.

17. Hansen IA, Attardo GM, Park J-H, Peng Q, Raikhel AS. Target of rapamycinmediated amino acid signaling in mosquito anautogeny. Proc Natl Acad Sci USA. 2004;101:10626-31.

18. Haac ME, Anderson MAE, Eggleston H, Myles KM, Adelman ZN. The hub protein loquacious connects the microRNA and short interfering RNA pathways in mosquitoes. Nucleic Acids Res. 2015;43:3688-700.

19. Xu Y, Yang $X$, Sun X, Li X, Liu Z, Yin Q, et al. Transcription factor FTZ-F1 regulates mosquito cuticular protein CPLCG5 conferring resistance to pyrethroids in Culex pipiens pallens. Parasit Vectors. 2020;13:514.

20. Evans AM. Mosquitoes of the Ethiopian Region. II.-Anophelini adults and early stages. London: British Museum (Natural History); 1938.

21. Balabanidou V, Kampouraki A, MacLean M, Blomquist GJ, Tittiger C, Juarez MP, et al. Cytochrome P450 associated with insecticide resistance catalyzes cuticular hydrocarbon production in Anopheles gambiae. Proc Natl Acad Sci USA. 2016;113:9268-73.

22. Balabanidou V, Kefi M, Aivaliotis M, Koidou V, Girotti JR, Mijailovsky SJ, et al. Mosquitoes cloak their legs to resist insecticides. Proc R Soc Lond B Biol Sci. 2019:286:1.

23. Wood O, Hanrahan S, Coetzee M, Koekemoer L, Brooke B. Cuticle thickening associated with pyrethroid resistance in the major malaria vector Anopheles funestus. Parasit Vectors. 2010;3:67.

24. Vannini L, Reed TW, Willis JH. Temporal and spatial expression of cuticular proteins of Anopheles gambiae implicated in insecticide resistance or differentiation of M/S incipient species. Parasit Vectors. 2014;7:24.
25. Yahouédo GA, Chandre F, Rossignol M, Ginibre C, Balabanidou V, Mendez NGA, et al. Contributions of cuticle permeability and enzyme detoxification to pyrethroid resistance in the major malaria vector Anopheles gambiae. Sci Rep. 2017;7:11091.

26. Vontas J, David JP, Nikou D, Hemingway J, Christophides GK, Louis $\mathrm{C}$, et al. Transcriptional analysis of insecticide resistance in Anopheles stephensi using cross-species microarray hybridization. Insect Mol Biol. 2007; 16:315-24

27. Nkya TE, Poupardin R, Laporte F, Akhouayri I, Mosha F, Magesa S, et al. Impact of agriculture on the selection of insecticide resistance in the malaria vector Anopheles gambiae: a multigenerational study in controlled conditions. Parasit Vectors. 2014;7:480.

28. Vannini L, Bowen JH, Reed TW, Willis JH. The CPCFC cuticular protein family: anatomical and cuticular locations in Anopheles gambiae and distribution throughout Pancrustacea. Insect Biochem Mol Biol. 2015;65:57-67.

29. Shahin $\mathrm{R}$, Iwanaga M, Kawasaki H. Cuticular protein and transcription factor genes expressed during prepupal-pupal transition and by ecdysone pulse treatment in wing discs of Bombyx mori. Insect Mol Biol. 2016;25:138-52.

30. Andersen SO. Amino acid sequence studies on endocuticular proteins from the desert locust. Schistocerca gregaria Insect Biochem Mol Biol. 1998;28:421-34.

31. Koella JC, Lyimo EO. Variability in the relationship between weight and wing length of Anopheles gambiae (Diptera: Culicidae). J Med Entomol. 1996:33:261-4.

\section{Publisher's Note}

Springer Nature remains neutral with regard to jurisdictional claims in published maps and institutional affiliations.
Ready to submit your research? Choose BMC and benefit from:

- fast, convenient online submission

- thorough peer review by experienced researchers in your field

- rapid publication on acceptance

- support for research data, including large and complex data types

- gold Open Access which fosters wider collaboration and increased citations

- maximum visibility for your research: over 100M website views per year

At BMC, research is always in progress.

Learn more biomedcentral.com/submissions 